\title{
The Role of Histone Acetylation in Memory Formation and Cognitive Impairments
}

\author{
Lucia Peixoto ${ }^{1}$ and Ted Abel ${ }^{*, 1}$ \\ ${ }^{1}$ Department of Biology, School of Arts and Sciences, University of Pennsylvania, Philadelphia, PA, USA
}

\begin{abstract}
Long-term memory formation requires transcription and protein synthesis. Over the past few decades, a great amount of knowledge has been gained regarding the molecular players that regulate the transcriptional program linked to memory consolidation. Epigenetic mechanisms have been shown to be essential for the regulation of neuronal gene expression, and histone acetylation has been one of the most studied and best characterized. In this review, we summarize the lines of evidence that have shown the relevance of histone acetylation in memory in both physiological and pathological conditions. Great advances have been made in identifying the writers and erasers of histone acetylation marks during learning. However, the identities of the upstream regulators and downstream targets that mediate the effect of changes in histone acetylation during memory consolidation remain restricted to a handful of molecules. We outline a general model by which corepressors and coactivators regulate histone acetylation during memory storage and discuss how the recent advances in highthroughput sequencing have the potential to radically change our understanding of how epigenetic control operates in the brain.
\end{abstract}

Neuropsychopharmacology Reviews (2013) 38, 62-76; doi: I0. I038/npp.20 I2.86; published online 6 June 2012

Keywords: learning and memory; cognition; molecular and cellular neurobiology; neuropharmacology; epigenetics; histone acetylation

\section{INTRODUCTION}

It has long been acknowledged that there can be long-lasting changes in phenotype that are not encoded in the DNA sequence of a cell. The term epigenetics was originally coined by Waddington in 1942 (Waddington, 1942) to explain phenotypic changes that occur from cell to cell during development. It was defined independently by Nanney in 1958 (Nanney, 1958) as 'auxiliary mechanisms involved in determining which specificities are to be expressed in any particular cell.' Allis et al (2007b) crystallized the molecular definition of epigenetics as 'the sum of the alterations to the chromatin template that collectively establish and propagate different patterns of gene expression (transcription) and silencing from the same genome'. Although once thought as a more or less irreversible process that happens in dividing cells, it is now known that epigenetic mechanisms can be dynamic. In

${ }^{*}$ Correspondence: $\operatorname{Dr} \mathrm{T}$ Abel, Department of Biology, University of Pennsylvania, Translational Research Center, Room 10-133, Building 421, 3400 Civic Center Boulevard, Philadelphia, PA 19104-6168, USA, Tel: +1 215898 3100, Fax: +1 215898 8780, E-mail: abele@sas.upenn.edu

Received 1 March 2012; revised 28 April 2012; accepted 30 April 2012 the past decade, considerable evidence has accumulated that the brain utilizes epigenetic marks to encode responses to environmental stimuli and their associated behaviors (Borrelli et al, 2008). Both histone acetylation and DNA methylation have been shown to play important roles in memory consolidation. This review focuses on understanding the role of one of these processes, histone acetylation, in the expression of a long-lasting but incredibly malleable behavior, memory. Histone acetylation has been the most characterized epigenetic mechanism involved in memory formation, and its relevance has been shown in both physiological and pathological conditions. However, a full understanding of the mechanisms by which histone acetylation controls the gene expression patterns that encode long-term memory remains elusive.

\section{Histone Acetylation and the Control of Gene Expression}

Gene expression in eukaryotes is greatly influenced by the status of chromatin, the complex of proteins and DNA that constitutes chromosomes and allows the linear genome to exist within the nucleus of a cell. Changes in chromatin structure regulate the accessibility and the recruitment of 
the transcriptional machinery to the DNA and hence determine if transcription can occur. The nucleosome, the fundamental unit of chromatin, is composed of an octamer of the four core histones ( $\mathrm{H} 3, \mathrm{H} 4, \mathrm{H} 2 \mathrm{~A}$, and $\mathrm{H} 2 \mathrm{~B})$ around which DNA is wrapped (Luger et al, 1997). Histone modifications encompass a variety of posttranslational modifications to the tails of histone proteins and are among the most studied forms of epigenetic mechanisms that control gene expression (Kouzarides, 2007). In particular, histone acetylation, which involves the addition of acetyl groups to lysines present in the N-terminal tails on the surface of the nucleosome, is associated with active transcription (Hebbes et al, 1988).

Originally, the model by which histone acetylation promotes transcription was based on the assumption that charge neutralization upon acetylation of lysines on histone tails would loosen the electrostatic attraction between DNA and histones and facilitate transcription (Davie and Chadee, 1998). Although it is clear that histone acetylation directly alters chromatin structure and accessibility, experiments in yeast and in vitro have suggested that charge neutralization is unlikely the cause (Choi and Howe, 2009). Yeast mutagenesis studies have shown that acetylation site substitutions from lysine to arginine and deletions on histone $\mathrm{H} 3$ tails both lead to GAL promoter hyperactivation (Mann and Grunstein, 1992). In vitro studies have also shown that the interaction between histone tails and DNA is not weakened by acetylation in physiological conditions (Mutskov et al, 1998). This evidence argues that the recognition of the acetylated lysines is likely more important than the change in charge itself, a point that probably applies to mammalian systems as well. More recent evidence has shown that acetylated histones are also able to serve as molecular tags. Proteins with bromodomains, which are frequently found in complexes that posttranslationally modify chromatin including transcriptional coactivators such as CBP, p300, and PCAF (Mujtaba et al, 2007; Sanchez and Zhou, 2009; Zeng and Zhou, 2002), are able to bind acetyllysines. Whether histone acetylation promotes transcription through direct chromatin remodeling, such as opening chromatin structure, or recruitment of other factors is still debated. Both mechanisms are not mutually exclusive and likely work in conjunction to affect gene expression.

The fact that histone modifications can recruit other proteins by recognition of the modified histone via protein domains is a central idea of the histone code hypothesis (Allis et al, 2007b; Jenuwein and Allis, 2001). The histone code hypothesis refers to the combination of modifications within and between histones that code for information not present in the DNA sequence and predicts that the modification marks on the histone tails should provide binding sites for proteins with regulatory functions that are able to 'read' such marks. How those modifications are established or removed is a key step in epigenetic regulation, and a wealth of work has shown that histone tail modifications are established ('written') or removed

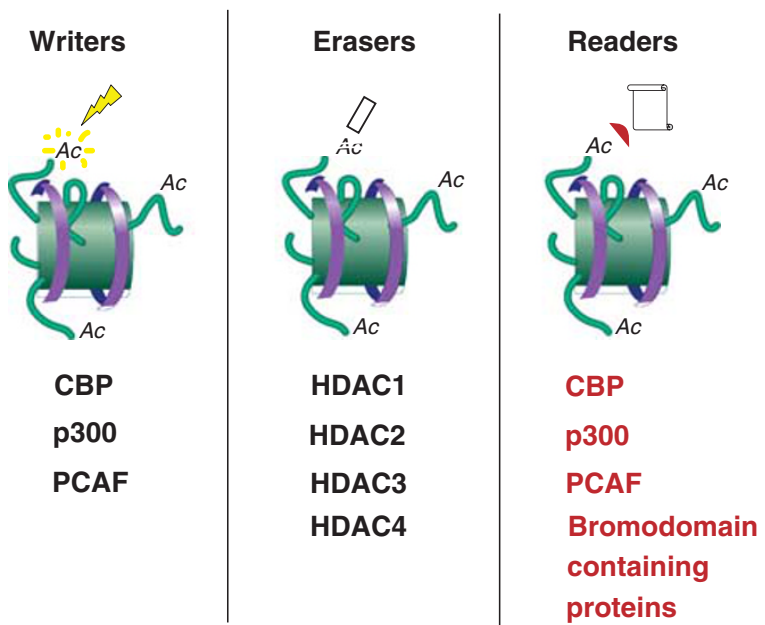

Figure 1. Writers, Erasers, and Readers of histone marks during longterm memory formation. Molecules that regulate acetylation of histone tails can be conceptually grouped into three categories (Borrelli et al, 2008): Writers, the enzymes that are able to add acetyl groups to the lysines in the tails (KATs); Erasers, the enzymes that remove the acetyl groups (KDACs); and Readers, the proteins that possess bromodomains and can recognize acetylated lysines (including KATs). For details on the evidence linking listed writers, erasers, and readers, see Tables 2 and 3.

('erased') by the action of chromatin-associated enzymatic complexes. As 'writers' of histone acetylation marks often possess bromodomains, they are able to 'read' the marks as well, creating the possibility of a positive feedback loop. The context dependence of the function of particular modifications, as well as the overlap between 'readers' and 'writers', has led to the proposal of a histone 'language' rather than a code (Lee et al, 2010) (Figure 1). It remains to be proven whether acetyl-lysine/bromodomain interactions are sufficient to mediate targeting of chromatin-modifying complexes to specific regions or require crosstalk with other types of modifications. However, increasing evidence has pointed to recruitment of 'readers' as the key function of histone acetylation (Yun et al, 2011). Hence, patterns of histone acetylation can induce transcription by direct recruitment of other proteins and not necessarily by destabilizing the interaction between histones and DNA, although both mechanisms are not mutually exclusive.

It was demonstrated early on that histone acetylation is rapid and reversible (DeLange and Smith, 1971). Levels of histone acetylation are controlled by the balance of proteins with histone acetyltransferase (HAT) and histone deacetylase (HDAC) activity. HATs are frequently transcriptional coactivators and possess bromodomains, whereas HDACs are usually part of corepressor complexes. Many HAT and HDAC enzymes have been shown to target nonhistone proteins, and were given a more generic name to reflect this phenomenon: lysine-acetyltransferases (KATs) and lysine deacetylases (KDACs; Allis et al, 2007a; Choudhary et al, 2009). Although the nomenclature of KATs has been changed to reflect this, the nomenclature of KDACs has remained the same as they already had a coherent nomenclature (Allis et al, 2007a). Therefore, individual 
KDACs will be named as HDAC1-11, whereas general lysine deacetylase function will be referred as KDAC. The availability of KDAC inhibitors and histone modificationspecific antibodies has allowed for a more thorough understanding of histone acetylation dynamics and its relationship with gene expression. Studies have shown that fast turnover of acetylation is tied to transcriptional activation (Waterborg, 2002). Binding of both KATs and KDACs to promoter regions is positively correlated with genome-wide gene expression (Wang et al, 2009). It has also been reported that the use of KDAC inhibitors can downregulate gene expression and acetylation levels at some promoters despite global increases in histone acetylation (Rada-Iglesias et al, 2007). Hence, the regulation of gene expression by histone acetylation functions likely through rapid turnover of histone marks and the dynamic recruitment of factors to the DNA that can themselves affect the function of the transcriptional machinery. Numerous studies have reported changes in histone acetylation and gene expression following diverse activating signals. However, one of the most notable examples of the role of histone acetylation in the regulation of biological function is its role in learning and memory formation.

\section{HISTONE ACETYLATION AND THE ESTABLISHMENT OF LONG-TERM MEMORY}

It has long been known that long-term memory formation requires transcription and protein synthesis in vivo (Agranoff et al, 1967; Flood et al, 1973). That requirement has also been demonstrated in ex vivo models of synaptic plasticity such as long-term potentiation (LTP) (Nguyen et al, 1994; Stanton and Sarvey, 1984). It has also been shown that this requirement is limited to 'critical periods' after learning (Bourtchouladze et al, 1998; Igaz et al, 2002), demonstrating that there is a necessary timeline of gene expression events. The regulation of transcription necessary for synaptic plasticity and long-term memory formation has been shown to be dependent on the cAMP response element-binding protein (CREB) as well as the NF- $\kappa$ B family of transcription factors (Albensi and Mattson, 2000; Gutierrez and Davies, 2011; Pittenger et al, 2002; Sakamoto et al, 2011). Several genes, in particular immediate-early genes (IEGs), have been implicated as targets, including c-fos, BDNF, Egr1, and the Nr4a family of transcription factors (Dragunow, 1996; Hawk and Abel, 2011a; Perez-Cadahia et al, 2011). More recently, it has been demonstrated that the regulation of transcription via histone acetylation is essential for memory formation, establishing epigenetic modifications as a potential mechanism for the persistence of long-term memory. However, it is still unclear how epigenetic changes are functionally related to specific transcriptional changes. In this section we summarize the lines of evidence that have linked histone acetylation to memory formation and what we know about the molecular pathways that underlie this phenomenon.

\section{Linking Acetylation to Memory: Global Changes in Histone Acetylation, KDAC Activity, and the Effects of KDAC Inhibitors in Learning}

Early studies using radioactive acetate incorporation showed that histone acetylation was increased in the hippocampus after training when compared with untrained controls, whereas histone acetylation was decreased in other brain regions such as the cortex (Schmitt and Matthies, 1979). More than two decades later, histone acetylation was shown to be a critical component of memory formation (Alarcon et al, 2004; Korzus et al, 2004; Levenson et al, 2004). KDAC inhibitors such as Trichostatin A (TSA) and sodium butyrate $(\mathrm{NaB})$ enhance LTP, and systemic injection of $\mathrm{NaB}$ enhances memory in vivo (Levenson et al, 2004). Intrahippocampal injection of TSA immediately after learning produces enhancements in long-term memory without affecting short-term memory (Vecsey et al, 2007), suggesting that histone acetylation is necessary for memory consolidation. Studies have also shown that injection of $\mathrm{NaB}$ can facilitate the formation of long-term memory for weak stimuli and enhance persistence of long-term memory (Stefanko et al, 2009). Hence, histone acetylation has a functional role in long-term memory formation.

Histone acetylation occurs at a variety of lysine positions within the four core histone proteins (Roth et al, 2001; Shahbazian and Grunstein, 2007; Suganuma and Workman, 2011). Chromatin immunoprecipitation (ChIP) studies have identified changes in acetylation at particular histones or positions within histones with long-term memory formation and synaptic plasticity. Table 1 summarizes these findings. Initial studies identified an increase in acetylation of histones $\mathrm{H} 3$ and $\mathrm{H} 4$ after 5-HT facilitation in Aplysia (Guan et al, 2002). Levenson et al (2004) then showed that acetylated levels of histone $\mathrm{H} 3$ increased $1 \mathrm{~h}$ after contextual fear conditioning in area $\mathrm{CA} 1$ of the hippocampus. Latent inhibition, however, increased histone $\mathrm{H} 4$ but not $\mathrm{H} 3$ acetylation. Forskolin stimulation of hippocampal slices induces acetylation of histone $\mathrm{H} 3 \mathrm{~K} 14$ but not of $\mathrm{H} 4$ (Chwang et al, 2007). BDNF treatment also induces $\mathrm{H} 3$ acetylation at $\mathrm{K} 9$ and $\mathrm{K} 14$ (Calfa et al, 2011). Studies in rats following Morris water maze training show increase in acetylation histones $\mathrm{H} 2 \mathrm{~B}, \mathrm{H} 3$, and $\mathrm{H} 4$, but only increases in $\mathrm{H} 2 \mathrm{~B}$ and $\mathrm{H} 4$ acetylation are exclusive to the hidden platform version of the task (Bousiges et al, 2010). Recent studies have shown an increase in acetylation of histones H3K9, $\mathrm{K} 14, \mathrm{H} 4 \mathrm{~K} 5, \mathrm{~K} 8$, and $\mathrm{K} 12$ (but not $\mathrm{K} 16$ ) at $1 \mathrm{~h}$ after contextual fear conditioning in healthy young mice (Peleg et al, 2010). A strong correlation has been reported between transcriptional activity and acetylation of the histone H3 and H4 lysine residues (Pokholok et al, 2005). The relationship between acetylation of $\mathrm{H} 2 \mathrm{~B}$ and gene expression is less well known, but it has been reported to mirror that of $\mathrm{H} 3$ and $\mathrm{H} 4$ only in the most transcribed genes (Myers et al, 2003). It is likely that acetylation of H2B, H3, and $\mathrm{H} 4$ has a role in memory storage. However, residues of histones $\mathrm{H} 3$ and $\mathrm{H} 4$ are acetylated and deacetylated by 
TABLE 1 Summary of Histone Acetylation Marks Shown to be Altered by Long-Term Memory Formation and Synaptic Plasticity

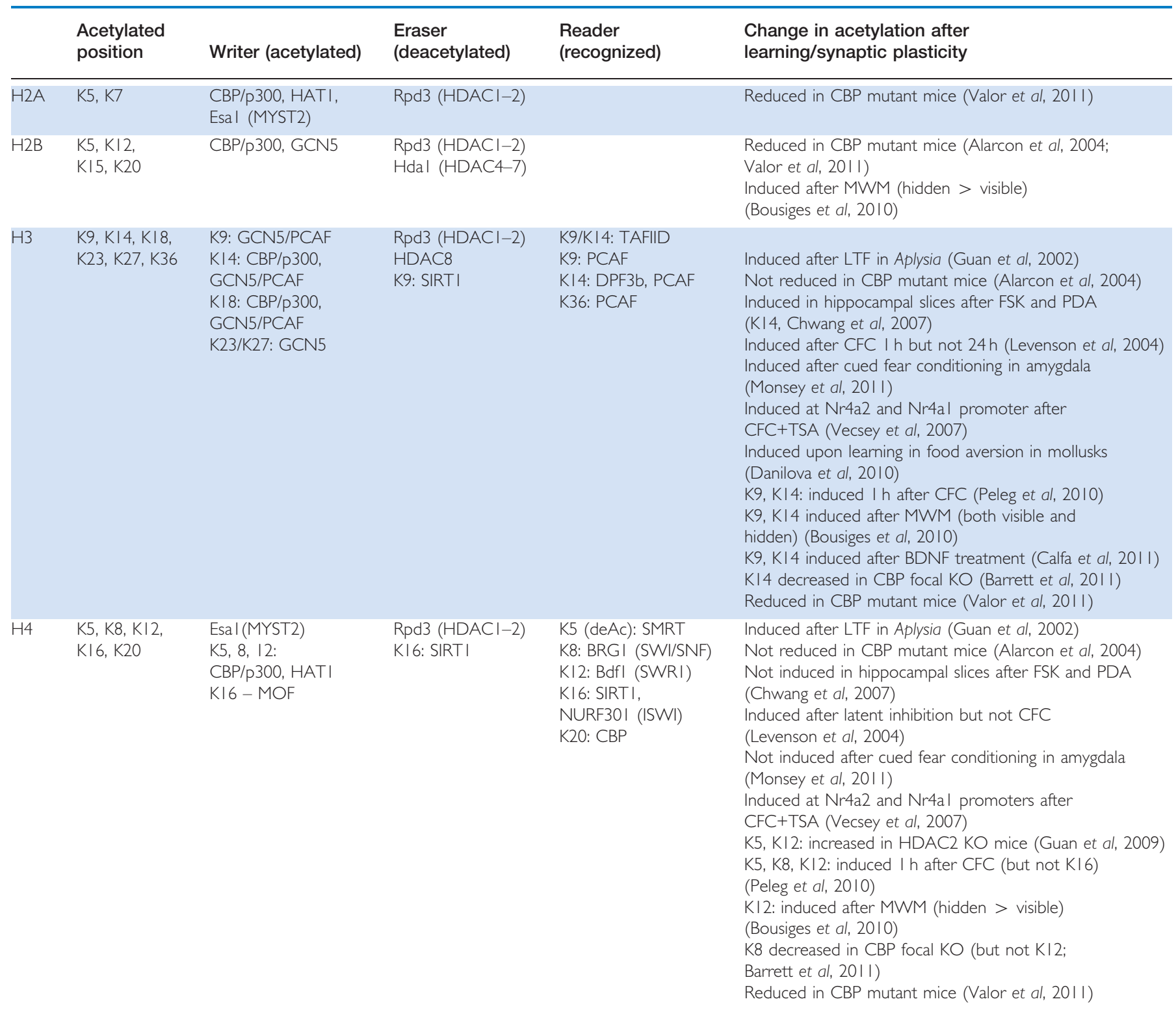

Abbreviations: CFC, contextual fear conditioning; MWM, Morris water maze.

Based on Shahbazian and Grunstein (2007) and Suganuma and Workman (20II).

Human/mouse orthologs of yeast proteins in columns 3, 4, and 5 (in parenthesis) were mapped using the OrthoMCL database (http://www.orthomcl.org). Individual residues in column 6 indicated when tested.

different enzymes and recruit different protein complexes (reviewed in Suganuma and Workman, 2011; summarized in Table 1). Hence, it is possible that different forms of learning will result in different patterns of acetylation at specific promoters that will lead to the activation of an overlapping yet slightly divergent transcriptional program.

Because inhibiting KDACs leads to memory enhancements, it is reasonable to propose that KDACs act as memory-suppressor genes (Abel et al, 1998). There are four classes of KDACs, based on sequence homology and domain structure. The use of selective gene knockout and siRNA gene suppression in conjunction with pharmacological approaches has allowed the study of the role of specific
KDACs in memory (see Table 2 for a summary of KDAC involvement in memory formation). TSA and $\mathrm{NaB}$ are broad class I and class II KDAC inhibitors (Dokmanovic et al, 2007). Using MS-275, a selective KDAC inhibitor, it has been recently demonstrated that class I KDAC inhibition is sufficient for memory enhancement (Hawk et al, 2011b). Overexpression of HDAC2 (but not HDAC1) decreases synaptic plasticity and memory formation and HDAC2 knockouts display memory enhancements (Guan et al, 2009). Although overexpression of HDAC1 does not disrupt initial memory consolidation, it has been recently shown to affect fear extinction (Bahari-Javan et al, 2012). Downregulation of HDAC3 using genetic and pharmacological 
TABLE 2 Summary of KDAC Involvement in Long-Term Memory Formation

\begin{tabular}{|c|c|c|c|c|c|c|}
\hline Class & KDAC & Localization & KDAC inhibitor & $\begin{array}{c}\text { Brain } \\
\text { Expression }^{\mathrm{a}}\end{array}$ & Interaction with other HDACs & Involvement in learning and memory \\
\hline \multirow[t]{3}{*}{$\bar{l}$} & $\mathrm{HDACl}$ & Nucleus & $\begin{array}{l}\text { TSA, MS275, VPA } \\
\text { NaB, SAHA }\end{array}$ & 0.3 & $\begin{array}{l}\text { HDAC2 ( } \operatorname{Sin} 3 \text {, NurD, and } \\
\text { CoREST complexes) }\end{array}$ & $\begin{array}{l}\text { No effect of overexpression in memory } \\
\text { (Guan et al, 2009) }\end{array}$ \\
\hline & HDAC2 & Nucleus & $\begin{array}{l}\text { TSA, MS275, VPA } \\
\text { NaB, SAHA }\end{array}$ & 1.6 & $\begin{array}{l}\mathrm{HDACl} \text { ( } \mathrm{Sin} 3, \mathrm{NurD} \text {, and } \\
\text { CoREST complexes) }\end{array}$ & $\begin{array}{l}\text { Overexpression suppresses memory and } \\
\text { deletion enhances (Guan et al, 2009), }\end{array}$ \\
\hline & HDAC3 & $\begin{array}{l}\text { Nucleus/cytoplasm, } \\
\text { plasma membrane }\end{array}$ & $\begin{array}{l}\text { TSA, MS275, VPA } \\
\text { NaB, RGFPI36, SAHA }\end{array}$ & 0.8 & HDACs 4,5 , and 7 & $\begin{array}{l}\text { Inhibition enhances memory } \\
\text { (McQuown et al, 20l I) }\end{array}$ \\
\hline \multirow[t]{3}{*}{$\| A$} & HDAC4 & Nucleus /cytoplasm & TSA, VAHA, NaB & - & HDAC3/SMRT/N-CoR complex & \\
\hline & HDAC5 & Nucleus/cytoplasm & TSA, VAHA, NaB & 7.2 & HDAC3/SMRT/N-CoR complex & $\begin{array}{l}\text { Recruitment blocks long-term facilitation } \\
\text { in Aplysia (Guan et al, 2002) }\end{array}$ \\
\hline & HDAC7 & Nucleus/cytoplasm & TSA, VAHA, NaB & 0.8 & HDAC3/SMRT/N-CoR complex & \\
\hline III & Sirtuins & & & - & & \\
\hline IV & HDACII & & & - & & \\
\hline
\end{tabular}

aEST, per/100000 tags.

bVPA does not inhibit class II HDACS at physiological concentrations (Fass et al, 20I0).

Based on McQuown and Wood (20I I) and Sengupta and Seto (2004).

approaches in the hippocampus is sufficient to enhance contextual fear memory (McQuown et al, 2011). HDAC5 recruitment blocks long-term facilitation in Aplysia (Guan et al, 2002). Class II KDACs (HDACs 4, 5, 7, and 10) are known to interact with class I HDACs, in particular with HDAC3-containing complexes (McQuown and Wood, 2011). It is likely that class I KDACs: HDAC1, HDAC2, and HDAC3, are involved in the epigenetic regulation of long-term memory; however, their individual contribution remains unclear. KDACs do not bind DNA directly but are a part of transcriptional multiprotein corepressor complexes (Sengupta and Seto, 2004). HDAC1 and HDAC2 are found together in corepressor complexes containing Sin3a, NurD, and CoREST. HDAC3 requires binding with the nuclear receptor corepressors $\mathrm{N}-\mathrm{CoR}$ or SMRT for activity. In vitro studies have demonstrated that recruitment of Sin3 corepressor complex results in deacetylation of histones $\mathrm{H} 3$ and $\mathrm{H} 4$, whereas recruitment of the N-CoR/SMRT complex results in deacetylation of histone $\mathrm{H} 3$ only (Vermeulen et al, 2004). These findings provide evidence that distinct $\mathrm{KDAC}$-containing corepressor complexes may play different roles in the regulation of transcription. It is also known that N-CoR interacts with Sin3a (Jones et al, 2001), and hence dissecting which of the KDACs found on those complexes is responsible for the transcriptional repression present in neurons may not be possible. It is likely that recruitment of both HDAC2 and HDAC3 corepressor complexes is relevant for memory consolidation but may vary with different learning or synaptic plasticity paradigms in a way that mirrors reported changes in $\mathrm{H} 3$ or $\mathrm{H} 4$ acetylation. An interesting observation is that the induction of $\mathrm{H} 3$ acetylation by BDNF treatment requires
KDAC activity and chronic TSA treatment actually inhibits further induction of histone acetylation and dendritic spine formation by BDNF (Calfa et al, 2011). Although this could be because of a ceiling effect, it is important to note that although KDAC inhibition produces memory enhancements in the short term, it could have the opposite effect with long-term exposure. Last, but not the least, the effects of KDAC inhibitors in learning may not be mediated exclusively through their effects on histone proteins, as acetylation of NF- $\kappa \mathrm{B}$ has been shown to improve long-term memory retention (Yeh et al, 2004). More studies are needed to understand the specific roles of HDAC2 and HDAC3, as well as other components of the corepressor complexes, in learning and memory formation.

Levels of histone acetylation have been shown to be changed in other brain regions besides the hippocampus, such as the lateral amygdala (Adachi et al, 2009; Monsey et al, 2011). Normal aging-related memory impairment is associated with the lack of histone $\mathrm{H} 4$ acetylation, which can be rescued by treatment with KDAC inhibitors to restore memory function (Peleg et al, 2010). Histone acetylation has also been shown to be induced after food aversion training in mollusks (Danilova et al, 2010), and overexpression as well as RNAi-mediated knockdown of histone deacetylase Rpd3 has been shown to impair longterm memory in Drosophila (Fitzsimons and Scott, 2011). Thus, the evidence argues that histone acetylation is a general mechanism of memory storage. It has been shown that the proportion of genes whose expression is responsive to KDAC inhibition in cell culture is $\sim 2 \%$ of expressed transcripts (Van Lint et al, 1996), and although histone acetylation is usually correlated with transcriptional activ- 
ity, it was demonstrated early on that TSA can differentially regulate CREB target genes by contributing to either activation or cessation of transcription (Fass et al, 2003). As the memory enhancement effects of KDAC inhibitors are dependent on transcription and translation, it is likely that the effects of histone acetylation in memory are restricted to a small subset of the genes that are altered. In the next section we discuss what is known regarding the molecular pathways that mediate the effects of histone acetylation in memory and their targets.

\section{Defining the Molecular Pathways that Lead to Changes in Histone Acetylation}

The regulation of transcription necessary for synaptic plasticity and long-term memory formation has been shown to be dependent on transcription factors CREB and NF- $\kappa$ B (Albensi and Mattson, 2000; Gutierrez and Davies, 2011; Pittenger et al, 2002; Sakamoto et al, 2011). CREB bindingprotein (CBP), a transcriptional coactivator with KAT activity, has also been shown to be essential for long-term memory formation. Several lines of CBP mutant mice have confirmed its essential role in learning; and memory and mutations in CBP cause Rubinstein-Taybi syndrome (RSTS), a neurodevelopmental disorder characterized by cognitive impairments (Alarcon et al, 2004; Bourtchouladze et al, 2003; Oike et al, 1999; Tanaka et al, 1997; Wood et al, 2005). Early on, it was demonstrated that CBP KAT activity was a critical component of memory consolidation (Korzus et al, 2004). It was also shown that the CREB-binding domain (KIX) is required for long-term memory (Wood et al, 2006). The effect of KDAC inhibitors in long-term memory has been shown to be CBP dependent and involve its interaction with CREB (Alarcon et al, 2004; Haettig et al, 2011; Korzus et al, 2004; Vecsey et al, 2007). Although all studies of CBP mutant mice have found memory impairments, the results regarding specific tasks have been contradictory. Varying performance in spatial navigation has been observed in different CBP mutant mice (Alarcon et al, 2004; Korzus et al, 2004). Despite multiple studies demonstrating a role for CBP in fear conditioning (Alarcon et al, 2004; Barrett et al, 2011; Chen et al, 2010; Korzus et al, 2004; Vecsey et al, 2007; Wood et al, 2005), some studies have not seen deficits in long-term fear conditioning (Valor et al, 2011), making object recognition the only task that is consistently affected. Not all deletions are complete and each of the mutants studied were not on identical inbred genetic backgrounds, which has been shown to be essential in studies of CREB (Graves et al, 2002). Therefore, a small population of CBP-positive neurons may be sufficient for learning paradigms that either involve several trials or generate persistent memories. It is also hard to determine whether the defects observed in the above models are because of developmental compensation, as most studies have relied on transgenic mice.

Recent studies have tried to address the effect of deleting CBP from the postnatal brain in a space-restricted manner, to isolate the role of CBP in learning away from its developmental effects. Chen et al (2010) showed that CBP seems to be required in excitatory neurons of the postnatal forebrain for both short-term and long-term memory formation. This is the first study to report short-term memory deficits in CBP mutants; however, the B6/129 hybrid background used in the study has been shown to exhibit short-term memory deficits when combined with CREB mutations (Graves et al, 2002), and hence it is unclear whether the deletion in CBP is indeed the cause of the deficit in short-term memory. Valor et al (2011) observed defects in novel object recognition but not in other memory tasks, such as contextual fear conditioning and Morris water maze. Focal deletion of CBP in hippocampal area CA1 using viral vectors impairs L-LTP (5 $\theta$ bursts) and long-term memory for contextual fear and object recognition (Barrett et al, 2011). Although it has been reported that $\mathrm{CBP}^{+/-}$ transgenics only show deficits in acetylation of $\mathrm{H} 2 \mathrm{~B}$, but not of $\mathrm{H} 3$ or $\mathrm{H} 4$ (Alarcon et al, 2004), focal deletion of CBP in the hippocampus produces deficits in H2BK12, H3K14, and H4K8 acetylation (Barrett et al, 2011) and forebrain deletion shows deficits in $\mathrm{H} 2 \mathrm{~A}, \mathrm{H} 2 \mathrm{~B}, \mathrm{H} 3$ and $\mathrm{H} 4$ acetylation (Valor et $a l, 2011)$. It is possible that global transgenic models show compensation during development or that newer lysine residue-specific antibodies are more sensitive. The deficit reported by Barrett et al (2011) is indeed greater in H2B acetylation, but $\mathrm{H} 4 \mathrm{~K} 8$ acetylation is affected whereas $\mathrm{H} 4 \mathrm{~K} 12$ is not, and hence an antibody that recognizes various forms of acetylated $\mathrm{H} 4$ will not be able to detect the difference. As mentioned before, different learning tasks seem to show differences in which specific histone marks are altered by training. Because H2B acetylation seems to be preferentially affected in CBP mutants, it is possible that learning paradigms whose transcriptional program is more dependent on $\mathrm{H} 2 \mathrm{~B}$ acetylation are affected to a greater extent. Overall, although it is clear that CBP plays a role in memory, and that the role is dependent on its KAT activity, the exact mechanism remains elusive. Determining the genes regulated by CBP is a crucial next step to understanding its role in memory.

Compensation of CBP function by expression of $\mathrm{CBP}$ paralogs may also be a confounding factor in the analysis of these different mutant mice. This is particularly a problem for constitutive CBP mutants, but compensatory induction of CBP paralogs could also occur on a short-time scale. p300, the closest homolog of CBP, is often able to acetylate the same residues. In addition to CBP, mutations in p300 have also been linked to RSTS (van Belzen et al, 2011). Studies of $\mathrm{p}^{300^{+/-}}$mice have suggested that the role of p300 in memory is less critical than that of CBP, as their cognitive impairments were mild (Viosca et al, 2010). However, expression of an inhibitory form of p300 as well as forebrain-specific postnatal knockdown has shown that p300 is required for long-term recognition and contextual fear memory (Oliveira et al, 2007, 2011). The role of p300 in memory is likely different from the role of CBP, as CREB/ CBP interaction is needed for motor learning whereas 
TABLE 3 Summary of KAT Involvement in Long-Term Memory Formation

\begin{tabular}{|c|c|c|c|}
\hline KAT group & $\begin{array}{l}\text { KAT (and complexes } \\
\text { associated) }\end{array}$ & $\begin{array}{l}\text { Interactions } \\
\text { with other KATs }\end{array}$ & Involvement in learning and synaptic plasticity \\
\hline GNAT & $\begin{array}{l}\text { KATI/HATI } \\
\text { KAT2A/GCN5 (SAGA, ADA, A2) } \\
\text { KAT2B/PCAF } \\
\text { KAT9/ELP3 (elongator) } \\
\text { LATI0/Hap2 }\end{array}$ & p300; CBP & $\begin{array}{l}\text { PCAF is required for short-term memory in young mice and } \\
\text { long-term in old mice (Maurice et al, 2008) }\end{array}$ \\
\hline p300/CBP & $\begin{array}{l}\text { KAT3A/CBP } \\
\text { KAT3B/P300 }\end{array}$ & PCAF; GCN5 & $\begin{array}{l}\text { p300 is required for long-term recognition and contextual } \\
\text { fear memory (Oliveira et al, 2007, 20I I, Viosca et al. 20 I0) } \\
\text { Memory impairments observed in several types of CBP mutant mice: } \\
\text { Hetereozygous knockout (Tanaka et al, 1997; Alarcon et al, 2004) } \\
\text { Dominant-negative (Oike et al, 1999; Bourtchouladze et al, 2003) } \\
\text { Spatially restricted transgenic dominant-negative (Wood et al, 2005) } \\
\text { Spatially and temporally restricted conditional transgenic dominant-negative } \\
\text { (Korzus et al, 2004) } \\
\text { Homozygous knockin (Wood et al, 2006) } \\
\text { Forebrain restricted postnatal knockout (Chen et al, 20I0; Valor et al, 20I I) } \\
\text { Local deletion using viral injections (Barrett et al, 20I I) }\end{array}$ \\
\hline $\begin{array}{l}\text { Basal transcription } \\
\text { factors }\end{array}$ & $\begin{array}{l}\text { KAT4/TAFI (TFIID) } \\
\text { KATI2/TFIIIC90 }\end{array}$ & & \\
\hline $\begin{array}{l}\text { Nuclear receptor } \\
\text { cofactors }\end{array}$ & $\begin{array}{l}\text { KATI3A/SRCI } \\
\text { KATI3B/ACTR } \\
\text { KATI3C/PI60 }\end{array}$ & & \\
\hline
\end{tabular}

Based on Allis et al (2007a) and Roth et al (200 I).

$\mathrm{CREB} / \mathrm{p} 300$ is not (Oliveira et al, 2006). It has also been reported that loss of $\mathrm{p} 300 / \mathrm{CBP}$-associated factor (PCAF) leads to short-term memory deficits in young mice and long-term memory deficits in older mice (Maurice et al, 2008). Table 3 summarizes our knowledge of the involvement of KATs in memory consolidation. However, unlike KDACs, the role of other KATs besides CBP/p300 in learning and synaptic plasticity remains largely unexplored. Figure 1 summarizes the known 'writers', 'readers', and 'erasers' of histone acetylation marks. Although the involvement of class I KDACs in learning and memory is clear, in particular HDAC2 and HDAC3, the role of KATs other than $\mathrm{CBP} / \mathrm{p} 300$ deserves further investigation. $\mathrm{CBP}$, p300, and PCAF all possess bromodomains and are likely readers of the histone marks as well as writers. The role of other bromodomain-containing proteins in memory has not been explored and warrants further investigation. Nonetheless, the largest unexplored areas regarding the role of histone acetylation in memory are the upstream signals that lead to changes in histone acetylation and the identity of the promoters of the genes that are regulated by such events.

\section{Upstream Pathways that Regulate Histone Acetylation in Memory Formation}

Several pathways have been shown to be required for longterm memory formation, including cyclic AMP/protein kinase A (cAMP/PKA), Ca2 + /calmodulin-dependent kinase (CAMK), and mitogen-activated protein kinase (MAPK) signaling (Morgado-Bernal, 2011). NMDA receptor activity and MAPK ERK signaling have been shown to be essential for histone $\mathrm{H} 3$ acetylation after contextual fear conditioning (Levenson et al, 2004). Other upstream components shown to be involved in learning-dependent chromatin remodeling are mitogen- and stress-activated protein kinase 1 (MSK1, RPS6KA5) and protein phosphatase 1 (PP1). Mice lacking MSK1, a nuclear kinase downstream of ERK, display impaired contextual fear learning and show decrease histone acetylation and phosphorylation after learning (Chwang et al, 2007). Interestingly, MSK1 has been implicated in the induction of several IEGs that have also been reported to be induced after learning. MSKs are required for the transcription of the nuclear orphan receptors Nur77, Nurr1, and Nor1 (Nr4a1, Nr4a2, and Nr4a3; Darragh et al, 2005). BDNF signaling has also been shown to induce histone acetylation changes (Zeng et al, 2011), and BDNF-induced expression of CREB-regulated genes $c$-fos and Nurr1 (Nr4a2) is impaired in MSK-deficient cortical neurons (Arthur et al, 2004). MSK1 is required for the phosphorylation of $\mathrm{CREB}, \mathrm{NF}-\kappa \mathrm{B}$, and histone $\mathrm{H} 3$ (Arthur, 2008). However, the relationship between MSK1 and histone acetylation is less clear. As MSK1 activates CREB, it is possible that the increase in acetylation is 
mediated by $\mathrm{CBP} / \mathrm{p} 300$ recruitment. PP1 is usually involved in dephosphorylating histone $\mathrm{H} 3$, among other substrates, and it has been shown to interact with KDACs (Brush et al, 2004). Selective inhibition of nuclear PP1 in forebrain neurons decreases KDAC activity in the hippocampus, increases acetylation of $\mathrm{H} 4 \mathrm{~K} 5$ and $\mathrm{H} 2 \mathrm{~B}$, and enhances memory for object recognition (Koshibu et al, 2009). Overexpression of PP1 decreases acetylation of H3K14 and $\mathrm{H} 4 \mathrm{~K} 5$, and could be mediated through KDAC recruitment. It has been shown that histone $\mathrm{H} 3$ phosphorylation and acetylation are synergistic modifications. Hence, the observed effect of both MSK1 and PP1 in histone acetylation and learning could be a result of crosstalk between histone acetylation and phosphorylation. Indeed, histone phosphorylation has also been shown to be associated with the consolidation of memory (Chwang et al, 2006, 2007).

\section{What Are the Genes Affected by Changes in Histone Acetylation During Learning?}

The link between histone acetylation and specific downstream targets has been limited to a small subset of genes, and there is not always a correlation with gene expression changes. The Bdnf promoter has been shown to be responsive to changes in histone acetylation after learning and synaptic plasticity. Transcription from $B d n f$ promoters 1 and 4 is activated when histone deacetylation is inhibited in vivo (Tsankova et al, 2006). Fear conditioning leads to an increase in histone $\mathrm{H} 3$ acetylation at $B d n f$ promoters 1 and 4 in rat prefrontal cortex, whereas extinction of conditioned fear is accompanied by an increase in histone $\mathrm{H} 4$ acetylation around promoter 4 (Bredy et al, 2007). However, increases in exon I and IV mRNA expression was only observed after extinction training. In rat hippocampal cultures, TSA increases $B d n f$ exon I transcription and H3K9/14 histone acetylation (Tian et al, 2010) and rescues age-dependent decline in hippocampal LTP and BDNF gene expression. It has also been shown that CBP is recruited to the $c$-fos promoter in an activity-dependent manner (Impey et al, 2002), and CBP KAT activity is required for $c$-fos gene expression (Korzus et al, 2004). However, c-fos induction after contextual fear conditioning did not change after TSA treatment (Vecsey et al, 2007), arguing that although histone acetylation may be necessary for $c$-fos induction after learning, it is not likely to mediate the TSA memory enhancements. On the other hand, CREB target genes $\mathrm{Nr} 4 a 1$ and $\mathrm{Nr} 4 \mathrm{a} 2$ expression as well as promoter acetylation are selectively increased after TSA inhibition (Vecsey et al, 2007). Interestingly, $N r 4 a 2$ binds to $B d n f$ promoter 4 , and silencing Nr4a2 by shRNA leads to a decrease in BDNF protein levels and a reduction of the effect of NMDA in neuronal survival (Barneda-Zahonero et al, 2012). CREBdependent neuroprotection has also been shown to be mediated by NR4A orphan receptors (Volakakis et al, 2010). The Creb promoter itself changes acetylation status after learning. Object recognition increases H3K14 acetylation at the Creb promoter whereas it decreases H3K9 and
$\mathrm{H} 4 \mathrm{~K} 5$ acetylation $24 \mathrm{~h}$ after training, a change that mirrors the increase in Creb gene expression (Koshibu et al, 2009). Overall, despite the great amount of evidence regarding the involvement of histone acetylation in long-term memory formation, candidate genes and promoters are lacking. Novel high-throughput sequencing technologies such as ChIP-seq are promising avenues to discover such candidates and shed further light on the molecular basis of longterm memory storage. It has been shown that sodium butyrate and TSA can often decrease acetylation levels at specific promoters despite their global increases in acetylation levels (Rada-Iglesias et al, 2007), and hence it is hard to predict what direction of change will be observed genomewide, and it is possible that genes that are functionally implicated in the establishment of long-term memory will show either increase or decrease of histone acetylation at their promoters.

Overall, several players have been uncovered in the regulation of genes expression by histone acetylation after learning. It is clear that KDACs and corepressor complexes play an important role in the repression of promoters in basal conditions, and their effect is regulated in an activity dependent-manner via recruitment of coactivators such as $\mathrm{CBP}$ and p300. Figure 2 presents a model for the regulation of histone acetylation during memory consolidation based on the data discussed. The regulation of the NR4A family of nuclear receptors has been proven to be one of the main targets of histone acetylation during memory formation. Hence, known components of their regulation (Hsu et al, 2004) have been incorporated into the model, adding elements of the corepressor complexes that may warrant exploration. For example, Cabin1, a calcineurin-dependent repressor that can recruit KDACs, can compete with p300 for binding of transcription factors such as MEF that can induce expression of Nr4a genes (Youn and Liu, 2000), establishing a direct link between calcium-dependent gene activation and histone acetylation.

\section{When Acetylation Goes Wrong: Dysregulation of Histone Acetylation and Cognitive Impairment}

In previous sections we have summarized the data that establish histone acetylation as an essential player in the processes that lead to long-term memory in physiological conditions. Dysregulation of histone acetylation has been reported in a variety of pathological conditions that impair cognitive function. Reports include mutations in known molecular players, changes in their expression, and/or changes in acetylation levels of specific histones.

\section{Neurodevelopmental Disorders}

As mentioned before, mutations of CBP and p300 have been linked to RSTS (van Belzen et al, 2011). RSTS is a welldefined syndrome with facial abnormalities, broad thumbs, broad big toes, and intellectual disability as the main clinical features (Rubinstein and Taybi, 1963). RSTS1 is 

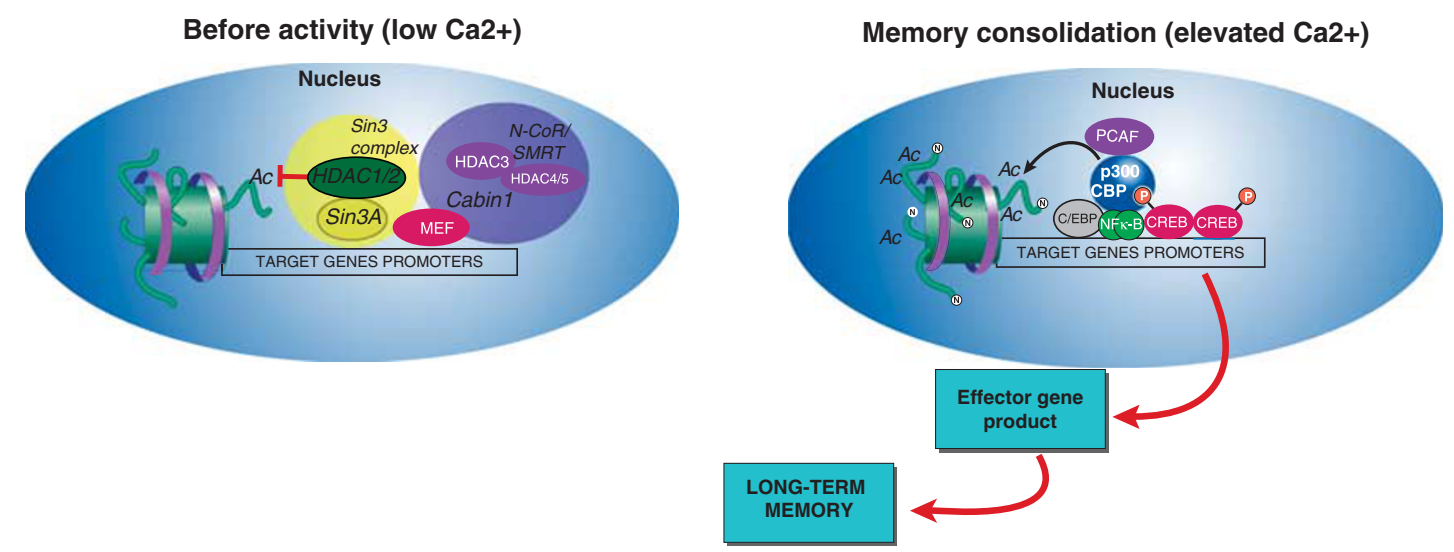

Figure 2. Regulation of gene expression by histone acetylation in the brain. On the left, a model of the proposed status of chromatin and corepressor complexes in basal state (low calcium) is presented, based on the data discussed in the review and the corepressor complexes known to regulate Nr4a1 expression. On the right, a model of the effect of neuronal activity and calcium influx on chromatin is presented, including coactivators. For simplicity, corepressor complexes are not depicted on the right; however, it is unclear whether they actually dissociate from chromatin.

defined by mutations in CBP and is found in $50-70 \%$ of the cases. RSTS2 is defined by mutations in p300 and is found in 3\% of the cases (Bartsch et al, 2010b). A small percentage of cases remain in which no genetic mutation has been identified, although other CBP paralogs have never been tested. It has also been shown that the degree of severity of the disease can be variable in relatives carrying the same mutation because of variable expression and somatic mosaicism (Bartsch et al, 2010a). This finding suggests that normal CBP expression is likely variable among cell types; hence, the role of CBP could be different in different regions of the brain. Floating-harbor syndrome (FLHS; Lacombe et al, 1995), which shows phenotypic overlap with RSTS, is caused by mutation in the Srcap gene, a coactivator of CBP. Interestingly, the only reported neurodevelopmental deficit in kids with FLHS is an expressive language delay. Therefore, it is possible that only a subset of the genes regulated by $\mathrm{CBP}$, defined by specific $\mathrm{CBP}$ coactivators, have a role in memory formation.

A link between histone acetylation and the expression of the Fmrl gene has been reported in Fragile X syndrome (FXS). FXS is caused by a trinucleotide expansion that produces the silencing of Fmr1 through DNA methylation (Pieretti et al, 1991). Treatment with class III HDAC inhibitors have been shown to induce Fmrl expression in cells derived from FXS patients (Biacsi et al, 2008). It has been shown that DNA methylation is coupled to histone acetylation and methylation in FXS patients (Tabolacci et al, 2008). These findings warrant further exploration of the role of histone acetylation in disorders in which DNA methylation is known to be affected, such as Rett Syndrome.

\section{Neurodegenerative Disorders}

Deficits in the expression of CBP, p300, and associated proteins have also been reported to be involved in the cognitive aspects of neurodegenerative disorders such as Alzheimer's disease (AD) and Huntington's disease (HD).
HD is caused by a CAG expansion in the coding region of the huntingtin gene that leads to a protein with an expanded polyglutamine track. The expansion has been shown to bind and inhibit the activity of the HAT domain of CBP and PCAF (Steffan et al, 2001). The long-term memory deficits in HD are correlated with reduced CBP levels and can be rescued by TSA administration (Giralt et al, 2012). Abnormal repression of $B d n f$ expression has been shown to be mediated by $\operatorname{Sin} 3 \mathrm{~A} / \mathrm{KDAC}$ complexes in cortical neurons expressing the mutant huntingtin protein (Landles and Bates, 2004). SAHA, a class I KDAC inhibitor, decreases HDAC2 and HDAC4 levels in vivo and improves molecular phenotypes in the R6/2 mouse model of HD (Mielcarek et al, 2011). Hence, it is clear that defects in CBP function are linked to the pathophysiology of HD.

Presenilin 1 and 2, the two primary genes known to cause familial $\mathrm{AD}$, are able to stimulate transcriptional activation by $\mathrm{CBP}$ and $\mathrm{p} 300$. This ability is disrupted in the AD mutant variants (Francis et al, 2007; Francis et al, 2006) implicating abnormal CBP/p300-mediated gene expression in the molecular basis of AD pathology. Nuclear localization of p300 interacting inhibitor of differentiation 1 (EID1), a $\mathrm{CBP} / \mathrm{p} 300$ inhibitory protein, has also been shown to play a role in AD pathogenesis (Liu et al, 2012). Systemic injection of HDAC inhibitors is able to rescue age-dependent memory deficits in a mouse model of $\mathrm{AD}$ (Kilgore et al, 2010). Increasing histone acetylation has been shown to reverse consolidation deficits in mouse models of induced neurodegeneration (Fischer et al, 2007; Fontan-Lozano et al, 2008), suggesting that manipulating the brain acetyl epigenome may be an effective way to treat the cognitive aspects of several brain disorders.

\section{Pharmacological Approaches for Manipulating the Brain Acetyl Epigenome and the Treatment of Psychiatric Disorders}

KDAC inhibitors have been shown to be neuroprotective in several mouse models of disease of the nervous 
system, including HD (Ferrante et al, 2003; Gardian et al, 2005), spinal muscular atrophy (Minamiyama et al, 2004), amyotrophic lateral sclerosis (Ryu et al, 2005), ischemia (Qi et al, 2004), Parkinson's disease (Gardian et al, 2004), and AD (Kilgore et al, 2010; Ricobaraza et al, 2009). The fact that several KDAC inhibitors are currently available and FDA approved to treat other disorders makes this class of drugs especially attractive. The possibility of using KDAC inhibitors to treat cognitive disorders has been extensively discussed and reviewed elsewhere (Fischer et al, 2010; Kazantsev and Thompson, 2008), and it is seen as a rational therapeutic approach based on the evidence discussed. Although the development of novel, potent, and specific KDAC inhibitor compounds is being actively pursued (Fass et al, 2010), their main drawback remains. As it has been made clear in this review, deacetylases are responsible for regulating diverse and important biological functions, and adverse effects are expected. Chronic KDAC treatment has been shown to lead to cognitive impairments (Adachi et al, 2009) and the failure of BDNF to induce dendrite outgrowth (Calfa et al, 2011). Most currently available KDAC inhibitors are pan-inhibitors, but it is not clear whether class-specific or isoform-specific inhibitors will be more efficacious.

The fact that Nr4a1 and Nr4a2 gene expression as well as promoter acetylation are selectively increased after TSA inhibition (Vecsey et al, 2007) suggests that the regulation of orphan nuclear receptors and their targets is an important downstream event in the regulation of long-term memory formation by histone acetylation. Nr4al has been extensively studied as a drug target in cancer, as compounds that induce Nr4a1 expression, including KDAC inhibitors, can induce apoptosis in cancerous cells (Safe et al, 2011). Several Nr4a family agonists have been described. These include: Cytosporone B (Csn-B), an agonist that activates the ligand-binding domain of NR4A1 and induces nuclear NR4A1-dependent gene expression (Zhan et al, 2008); 6-Mercaptopurine (6-MP) and anticancer agent that induces $N r 4 a$ receptor expression and NR4A2 and NR4A3 transactivation (Ordentlich et al, 2003; Wansa et al, 2003; Yoo et al, 2007); and substituted benzimidazoles (Dubois et al, 2006) and isoxazolopyridinones (Hintermann et al, 2007). The consequences of activating NR4A receptor signaling pharmacologically in cognitive function remains unexplored, but it constitutes a promising new avenue for the rational design of compounds to treat cognitive disorders. Although the focus of therapeutic development has been mostly on more specific and potent KDAC inhibitors, the fact that a single family of effector proteins such as NR4A receptors can provide several potential new drug targets exemplifies why knowing more about the downstream genes affected by histone acetylation is a promising avenue for the development of novel rationally designed drugs that treat cognitive impairments.

\section{FUTURE RESEARCH DIRECTIONS: THE IMPACT OF NEXT-GENERATION SEQUENCING ON THE STUDY OF THE MEMORY EPIGENOME}

Despite the considerable advances in the understanding of the histone acetylation changes caused by long-term memory formation, the identity of the genes subject to epigenetic regulation remains a largely unexplored question. The use of genome-wide high-throughput technologies for discovery-based studies in now commonplace in biomedical research. Hence, there is tremendous potential for the discovery of novel candidates whose histone acetylation state is a functional consequence of memory consolidation using these technologies. A great amount of the study of the regulation of genome-wide gene expression involves the identification of protein/DNA interactions, which include the binding patterns of transcription factors and modified histones to the genome. ChIP is usually the basis of such experiments, which are then followed by a genome-wide identification of the DNA elements that are enriched by the precipitation step. Although originally done using DNA arrays (ChIP-chip), advancement in highthroughput sequencing technologies have replaced the use of arrays for sequencing. ChIP-seq is the sequencing of the genomic DNA fragments that coprecipitate with a DNAbinding protein that is under study. As the technique does not rely on prior knowledge of precise DNA-binding sites, theoretically, ChIP-seq can identify in an unbiased manner all DNA segments in the genome physically associated with a specific DNA-binding protein. The details of ChIP-seq technology have been extensively reviewed elsewhere (Kharchenko et al, 2008; Park, 2009; Pepke et al, 2009; Zhou et al, 2011a) and are beyond the scope of this review, but in order to evaluate their potential in helping define the memory epigenome, it is useful to understand its strengths and caveats. Genomic approaches are rarely unbiased, which, combined with the number of simultaneous experiments performed, limits their ability to actually answer the hypotheses we wish to test. A genome-wide perspective relies heavily on computational processing and the results more often than not defy conventional wisdom. The development of new technologies for genome-wide studies is fast paced, but its use and the development of the bioinformatics infrastructure for the processing of the data that these technologies generate often lags behind. In this section we will briefly discuss what has been learned from the study of genome-wide chromatin regulation outside the brain and the advantages and pitfalls of the application of ChIP-seq to the study of long-term memory in vivo.

\section{Studying Genome-Wide Gene Regulation: What Have We Learned?}

Systematic identification of DNA elements involved in the regulation of gene expression through high-throughput approaches has been a relatively recent concern in higher 
eukaryotes. Early ChIP-chip studies established that highresolution maps of the state of histone tail modifications in human cells and Drosophila can provide insights on the regulatory state of chromatin (Bernstein et al, 2005; Schubeler et al, 2004). The first published results of The ENCyclopedia of DNA Elements (ENCODE) project provided further insight into the relationship between histone modifications and genome-wide transcriptional activation (Birney et al, 2007). Acetylation of histone $\mathrm{H} 3$, among other marks, was found to be highly predictive of gene activity (Koch et al, 2007), whereas at the same time administration of KDAC inhibitor butyrate was found to decrease histone acetylation at transcription start sites and downregulate associated genes (Rada-Iglesias et al, 2007). The findings seem contradictory at first, as blocking KDACs increases global acetylation that theoretically should upregulate many genes. However, although KDAC inhibitor treatment regulates $\sim 5-20 \%$ of the transcriptome, it was shown previously that it often downregulates equal or greater number of genes than it upregulates (Daly and ShiraziBeechey, 2006) (de Ruijter et al, 2005; Peart et al, 2005). Recent data have shown that butyrate-induced acetylation in $\mathrm{H} 3 \mathrm{~K} 9$ and $\mathrm{H} 3 \mathrm{~K} 27$ changes the sequence-based binding preference of histone $\mathrm{H} 3$ and may explain the observed pattern of gene expression regulation induced by KDAC inhibitors (Shin et al, 2012). The ENCODE findings highlight the fact that the meaning of areas that are enriched in histone acetylation in a given sample ('Peaks') when compared with nonprecipitated DNA ('Input') is not the same as the meaning of the changes in histone acetylation enrichment between samples with different treatments. In other words, although peaks in histone acetylation are usually found at the transcription start site of most genes that will be expressed by a particular cell type, a particular stimulus can induce subtle changes in the size and shape of those peaks that will affect expression levels at a given time. In essence, this reflects the difference between the role of histone acetylation in the maintenance of a particular cell type-specific expression profile and its dynamic role in transcriptional regulation. Most of the available ChIP-seq analysis software focus on the detection of peaks relative to input DNA control; they are in essence peak-finding tools. However, no available algorithm exists that will detect statistically significant differences in peak shape and size between treatments, such as learning and controls. The development of bioinformatics tools for nextgeneration sequencing analysis, however, is extremely fast paced, and hence this is likely to change in the near future.

\section{The Challenges of Defining the Learning Epigenome}

There are several reasons that make the analysis of ChIP-seq data a complicated task, and some issues are particularly difficult for the study of genome-wide changes in histone acetylation induced by learning. Several steps of the Chipseq procedure introduce biases (Park, 2009); hence, the use of controls is essential and has been shown to have a huge impact in peak-calling (Ho et al, 2011). Another important source of variation in the analysis of ChIP-seq profiles originates from the use of different analysis algorithms, and it has been shown that the variability introduced by using different algorithms can be as high as the variability between using ChIP-chip vs. ChIP-seq (Ho et al, 2011). The ability to detect a peak, biases aside, depends directly on the signal-to-noise ratio. The fact that genome-wide approaches test tens of thousands of events simultaneously, and hence require multiple testing correction, makes this requirement even stricter.

One of the biggest challenges when studying a physiological stimulus like learning in vivo is that the signal is subtle and the noise is high. At any given time it is likely that some other stimulus besides the learning experience is causing changes in gene expression or histone acetylation (eg, the presence of females in the holding room if the subjects are male) as it is virtually impossible to isolate the animal from its environment. The only way to control this is to randomize all possible sources of variation so that they can be removed at a later point in the analysis. An effective way to improve the detection of signal over noise is to increase the number of biological replicates in the study; however, the high cost of sequencing makes this difficult to achieve. Also, not all the cells that are collected in a sample are responding to the stimulus of interest, which dilutes the signal. Because we assume that activity-dependent changes occur in activated neurons, an alternative approach would be to tag histones in the cell populations of interest. For example, H2B-GFP mice generated by Jiang et al (2008) can be used to isolate excitatory neurons in the hippocampus. In those mice, histone $2 \mathrm{~B}$-GFP fusion protein is expressed under the control of forebrain-specific CamkII promoter. Sequential ChIP for GFP and then the histone modification of interest can be used to isolate DNA for further sequencing.

In summary, proper randomization of the experimental design combined with a high number of biological replicates and enrichment in the cell population of interest will greatly increase the chance of a successful ChIP-seq experiment in the context of learning. A handful of recent studies have use ChIP-seq technology to study changes in epigenetic marks (including transcription factor binding) in the context of brain and behavior (Kramer et al, 2011; Tang et al, 2011; Zhou et al, 2011b), and only one has studied changes in histone acetylation after learning (Peleg et al, 2010). The reproducibility of the results given the lack of biological replicates remains in question, as there are not reported $P$-values for the detected differences. For example, although H4K12 was shown to be increased in the promoters of genes upregulated by fear conditioning in 3month-old mice by ChIP-seq (Peleg et al, 2010), the study fails to reproduce the result using ChIP-PCR at the promoters of the candidate genes tested. An interesting point to note is that the integration of other types of genome-wide data sets (in this case, gene expression), can 
often help in narrowing down functionally meaningful results. The biggest hurdle in the use of ChIP-seq technology for the study of learning and memory remains the fact that the interesting question is not finding the peaks, but what the differences in peak size and shape induced by learning are. Unfortunately, the algorithms to ask that question taking account statistical significance are not yet available.

Whole genome expression studies should, when possible, accompany ChIP-seq studies, and although RNA-seq has its own inherent biases, the challenges in terms of experimental design are the same as outlined above for ChIP-seq studies. The immense amount of data produced by next-generation sequencing means a heavy reliance on computational methods, which in turn requires controls to evaluate their performance. Hence, candidate-gene approaches should be pursued in parallel, not only for the validation of genomescale studies but preferably before the execution of genomewide sequencing studies to serve as positive controls. The integration of 'top-down' and 'bottom-up' approaches will likely constitute the future avenue of research for many years to come as we strive to define the epigenetic language of long-term memory. Overall, there is great promise in the use of next-generation sequencing technologies to define the downstream candidates of histone acetylation that are relevant for memory formation. Identifying the downstream effectors of the changes in histone acetylation produced by memory consolidation will in turn lead to a better chance toward the rational design of drugs that target the epigenome to treat brain disorders that alter cognitive function.

\section{ACKNOWLEDGEMENTS}

We thank Shane Poplawski and Marcel Estévez for valuable discussions. This publication was made possible by the support of post-doctoral NRSA training Grant NS007413 (to $\mathrm{L}$ Peixoto, principal investigator $\mathrm{M}$ Robinson) and R01MH087463 (to T Abel).

\section{DISCLOSURE}

The authors declare that, except for income received from the primary employer and the acknowledged NIH grants, no financial support or compensation has been received from any other individual or corporate entity in the past 3 years and there are no personal financial holdings that could be perceived as constituting a potential conflict of interest.

\section{REFERENCES}

Abel T, Martin KC, Bartsch D, Kandel ER (1998). Memory suppressor genes: inhibitory constraints on the storage of long-term memory. Science 279: 338-341.

Adachi M, Autry AE, Covington III HE, Monteggia LM (2009). MeCP2-mediated transcription repression in the basolateral amygdala may underlie heightened anxiety in a mouse model of Rett syndrome. J Neurosci 29: 4218-4227.

Agranoff BW, Davis RE, Casola L, Lim R (1967). Actinomycin D blocks formation of memory of shock-avoidance in goldfish. Science 158: 1600-1601.
Alarcon JM, Malleret G, Touzani K, Vronskaya S, Ishii S, Kandel ER et al (2004). Chromatin acetylation, memory, and LTP are impaired in CBP+/- mice: a model for the cognitive deficit in Rubinstein-Taybi syndrome and its amelioration. Neuron 42: 947-959.

Albensi BC, Mattson MP (2000). Evidence for the involvement of TNF and NF-kappaB in hippocampal synaptic plasticity. Synapse 35: 151-159.

Allis CD, Berger SL, Cote J, Dent S, Jenuwien T, Kouzarides Tet al (2007a). New nomenclature for chromatin-modifying enzymes. Cell 131: 633-636.

Allis CD, Jenuwein T, Reinberg D (eds) (2007b). Epigenetics. Cold Spring Harbor Laboratory Press: Cold Spring Harbor, NY.

Arthur JS (2008). MSK activation and physiological roles. Front Biosci 13: 5866-5879.

Arthur JS, Fong AL, Dwyer JM, Davare M, Reese E, Obrietan K et al (2004). Mitogen- and stress-activated protein kinase 1 mediates cAMP response element-binding protein phosphorylation and activation by neurotrophins. J Neurosci 24: 4324-4332.

Bahari-Javan S, Maddalena A, Kerimoglu C, Wittnam J, Held T, Bahr M et al (2012). HDAC1 regulates fear extinction in mice. J Neurosci 32: 5062-5073.

Barneda-Zahonero B, Servitja JM, Badiola N, Minano-Molina AJ, Fado R, Saura CA et al (2012). Nurr1 is required for NMDA receptor-mediated neuronal survival. J Biol Chem; e-pub ahead of print 31 January 2012.

Barrett RM, Malvaez M, Kramar E, Matheos DP, Arrizon A, Cabrera SM et al (2011). Hippocampal focal knockout of CBP affects specific histone modifications, longterm potentiation, and long-term memory. Neuropsychopharmacology 36: 1545-1556.

Bartsch O, Kress W, Kempf O, Lechno S, Haaf T, Zechner U (2010a). Inheritance and variable expression in Rubinstein-Taybi syndrome. Am J Med Genet A 152A: 2254-2261.

Bartsch O, Labonte J, Albrecht B, Wieczorek D, Lechno S, Zechner U et al (2010b). Two patients with EP300 mutations and facial dysmorphism different from the classic Rubinstein-Taybi syndrome. Am J Med Genet A 152A: 181-184.

Bernstein BE, Kamal M, Lindblad-Toh K, Bekiranov S, Bailey DK, Huebert DJ et al (2005). Genomic maps and comparative analysis of histone modifications in human and mouse. Cell 120: 169-181.

Biacsi R, Kumari D, Usdin K (2008). SIRT1 inhibition alleviates gene silencing in Fragile X mental retardation syndrome. PLoS Genet 4: e1000017.

Birney E, Stamatoyannopoulos JA, Dutta A, Guigo R, Gingeras TR, Margulies EH et al (2007). Identification and analysis of functional elements in $1 \%$ of the human genome by the ENCODE pilot project. Nature 447: 799-816.

Borrelli E, Nestler EJ, Allis CD, Sassone-Corsi P (2008). Decoding the epigenetic language of neuronal plasticity. Neuron 60: 961-974.

Bourtchouladze R, Abel T, Berman N, Gordon R, Lapidus K, Kandel ER (1998). Different training procedures recruit either one or two critical periods for contextual memory consolidation, each of which requires protein synthesis and PKA. Learn Mem 5: 365-374.

Bourtchouladze R, Lidge R, Catapano R, Stanley J, Gossweiler S, Romashko D et al (2003). A mouse model of Rubinstein-Taybi syndrome: defective long-term memory is ameliorated by inhibitors of phosphodiesterase 4. Proc Natl Acad Sci USA 100: 10518-10522.

Bousiges O, Vasconcelos AP, Neidl R, Cosquer B, Herbeaux K, Panteleeva I et al (2010). Spatial memory consolidation is associated with induction of several lysine-acetyltransferase (histone acetyltransferase) expression levels and H2B/ H4 acetylation-dependent transcriptional events in the rat hippocampus. Neuropsychopharmacology 35: 2521-2537.

Bredy TW, Wu H, Crego C, Zellhoefer J, Sun YE, Barad M (2007). Histone modifications around individual BDNF gene promoters in prefrontal cortex are associated with extinction of conditioned fear. Learn Mem 14: 268-276.

Brush MH, Guardiola A, Connor JH, Yao TP, Shenolikar S (2004). Deactylase inhibitors disrupt cellular complexes containing protein phosphatases and deacetylases. J Biol Chem 279: 7685-7691.

Calfa G, Chapleau CA, Campbell S, Inoue T, Morse SJ, Lubin FD et al (2011). HDAC activity is required for BDNF to increase quantal neurotransmitter release and dendritic spine density in CA1 pyramidal neurons. Hippocampus; e-pub ahead of print 7 December 2011.

Chen G, Zou X, Watanabe H, van Deursen JM, Shen J (2010). CREB binding protein is required for both short-term and long-term memory formation. J Neurosci 30: 13066-13077.

Choi JK, Howe LJ (2009). Histone acetylation: truth of consequences? Biochem Cell Biol 87: 139-150.

Choudhary C, Kumar C, Gnad F, Nielsen ML, Rehman M, Walther TC et al (2009). Lysine acetylation targets protein complexes and co-regulates major cellular functions. Science 325: 834-840.

Chwang WB, Arthur JS, Schumacher A, Sweatt JD (2007). The nuclear kinase mitogen- and stress-activated protein kinase 1 regulates hippocampal chromatin remodeling in memory formation. J Neurosci 27: 12732-12742. 
Chwang WB, O'Riordan KJ, Levenson JM, Sweatt JD (2006). ERK/MAPK regulates hippocampal histone phosphorylation following contextual fear conditioning. Learn Mem 13: 322-328.

Daly K, Shirazi-Beechey SP (2006). Microarray analysis of butyrate regulated genes in colonic epithelial cells. DNA Cell Biol 25: 49-62.

Danilova AB, Kharchenko OA, Shevchenko KG, Grinkevich LN (2010). Histone H3 acetylation is asymmetrically induced upon learning in identified neurons of the food aversion network in the Mollusk Helix Lucorum. Front Behav Neurosci 4: 180.

Darragh J, Soloaga A, Beardmore VA, Wingate AD, Wiggin GR, Peggie M et al (2005). MSKs are required for the transcription of the nuclear orphan receptors Nur77, Nurr1 and Nor1 downstream of MAPK signalling. Biochem J 390(Part 3): 749-759.

Davie JR, Chadee DN (1998). Regulation and regulatory parameters of histone modifications. J Cell Biochem Supp/ 30-31: 203-213.

de Ruijter AJ, Meinsma RJ, Bosma P, Kemp S, Caron HN, van Kuilenburg AB (2005). Gene expression profiling in response to the histone deacetylase inhibitor BL1521 in neuroblastoma. Exp Cell Res 309: 451-467.

DeLange RJ, Smith EL (1971). Histones: structure and function. Annu Rev Biochem 40: 279-314.

Dokmanovic M, Clarke C, Marks PA (2007). Histone deacetylase inhibitors: overview and perspectives. Mol Cancer Res 5: 981-989.

Dragunow M (1996). A role for immediate-early transcription factors in learning and memory. Behav Genet 26: 293-299.

Dubois C, Hengerer B, Mattes $\mathrm{H}$ (2006). Identification of a potent agonist of the orphan nuclear receptor Nurr1. ChemMedChem 1: 955-958.

Fass DM, Butler JE, Goodman RH (2003). Deacetylase activity is required for cAMP activation of a subset of CREB target genes. J Biol Chem 278: 43014-43019.

Fass DM, Shah R, Ghosh B, Hennig K, Norton S, Zhao WN et al (2010). Effect of inhibiting histone deacetylase with short-chain carboxylic acids and their hydroxamic acid analogs on vertebrate development and neuronal chromatin. ACS Med Chem Lett 2: 39-42.

Ferrante RJ, Kubilus JK, Lee J, Ryu H, Beesen A, Zucker B et al (2003). Histone deacetylase inhibition by sodium butyrate chemotherapy ameliorates the neurodegenerative phenotype in Huntington's disease mice. J Neurosci 23: 9418-9427.

Fischer A, Sananbenesi F, Mungenast A, Tsai LH (2010). Targeting the correct HDAC(s) to treat cognitive disorders. Trends Pharmacol Sci 31: 605-617.

Fischer A, Sananbenesi F, Wang X, Dobbin M, Tsai LH (2007). Recovery of learning and memory is associated with chromatin remodelling. Nature 447: 178-182.

Fitzsimons HL, Scott MJ (2011). Genetic modulation of Rpd3 expression impairs long-term courtship memory in Drosophila. PLoS One 6: e29171.

Flood JF, Rosenzweig MR, Bennett EL, Orme AE (1973). The influence of duration of protein synthesis inhibition on memory. Physiol Behav 10: 555-562.

Fontan-Lozano A, Romero-Granados R, Troncoso J, Munera A, Delgado-Garcia JM, Carrion AM (2008). Histone deacetylase inhibitors improve learning consolidation in young and in KA-induced-neurodegeneration and SAMP-8mutant mice. Mol Cell Neurosci 39: 193-201.

Francis YI, Diss JK, Kariti M, Stephanou A, Latchman DS (2007). p300 activation by Presenilin 1 but not by its M146L mutant. Neurosci Lett 413: 137-140.

Francis YI, Stephanou A, Latchman DS (2006). CREB-binding protein activation by presenilin 1 but not by its M146L mutant. NeuroReport 17: 917-921.

Gardian G, Browne SE, Choi DK, Klivenyi P, Gregorio J, Kubilus JK et al (2005). Neuroprotective effects of phenylbutyrate in the $\mathrm{N} 171-82 \mathrm{Q}$ transgenic mouse model of Huntington's disease. J Biol Chem 280: 556-563.

Gardian G, Yang L, Cleren C, Calingasan NY, Klivenyi P, Beal MF (2004). Neuroprotective effects of phenylbutyrate against MPTP neurotoxicity. Neuromolecular Med 5: 235-241.

Giralt A, Puigdellivol M, Carreton O, Paoletti P, Valero J, Parra-Damas A et al (2012). Long-term memory deficits in Huntington's disease are associated with reduced CBP histone acetylase activity. Hum Mol Genet 21: 1203-1216.

Graves L, Dalvi A, Lucki I, Blendy JA, Abel T (2002). Behavioral analysis of CREB alphadelta mutation on a B6/129 F1 hybrid background. Hippocampus 12: 18-26.

Guan JS, Haggarty SJ, Giacometti E, Dannenberg JH, Joseph N, Gao J et al (2009). HDAC2 negatively regulates memory formation and synaptic plasticity. Nature 459: 55-60.

Guan Z, Giustetto M, Lomvardas S, Kim JH, Miniaci MC, Schwartz JH et al (2002). Integration of long-term-memory-related synaptic plasticity involves bidirectional regulation of gene expression and chromatin structure. Cell 111: 483-493.

Gutierrez H, Davies AM (2011). Regulation of neural process growth, elaboration and structural plasticity by NF-kappaB. Trends Neurosci 34: 316-325.

Haettig J, Stefanko DP, Multani ML, Figueroa DX, McQuown SC, Wood MA (2011). HDAC inhibition modulates hippocampus-dependent long-term memory for object location in a CBP-dependent manner. Learn Mem 18: 71-79.
Hawk JD, Abel T (2011a). The role of NR4A transcription factors in memory formation. Brain Res Bull 85: 21-29.

Hawk JD, Florian C, Abel T (2011b). Post-training intrahippocampal inhibition of class I histone deacetylases enhances long-term object-location memory. Learn Mem 18: 367-370

Hebbes TR, Thorne AW, Crane-Robinson C (1988). A direct link between core histone acetylation and transcriptionally active chromatin. EMBO $\mathrm{J}$ : 1395-1402.

Hintermann S, Chiesi M, von Krosigk U, Mathe D, Felber R, Hengerer B (2007). Identification of a series of highly potent activators of the Nurr1 signaling pathway. Bioorg Med Chem Lett 17: 193-196.

Ho JW, Bishop E, Karchenko PV, Negre N, White KP, Park PJ (2011). ChIP-chip versus ChIP-seq: lessons for experimental design and data analysis. BMC Genomics 12: 134

Hsu HC, Zhou T, Mountz JD (2004). Nur77 family of nuclear hormone receptors. Curr Drug Targets Inflamm Allergy 3: 413-423.

Igaz LM, Vianna MR, Medina JH, Izquierdo I (2002). Two time periods of hippocampal mRNA synthesis are required for memory consolidation of fearmotivated learning. J Neurosci 22: 6781-6789.

Impey S, Fong AL, Wang Y, Cardinaux JR, Fass DM, Obrietan K et al (2002). Phosphorylation of CBP mediates transcriptional activation by neural activity and CaM kinase IV. Neuron 34: 235-244.

Jenuwein T, Allis CD (2001). Translating the histone code. Science 293: 1074-1080. Jiang Y, Matevossian A, Huang HS, Straubhaar J, Akbarian S (2008). Isolation of neuronal chromatin from brain tissue. BMC Neurosci 9: 42.

Jones PL, Sachs LM, Rouse N, Wade PA, Shi YB (2001). Multiple N-CoR complexes contain distinct histone deacetylases. J Biol Chem 276: 8807-8811.

Kazantsev AG, Thompson LM (2008). Therapeutic application of histone deacetylase inhibitors for central nervous system disorders. Nat Rev Drug Discov 7: 854-868.

Kharchenko PV, Tolstorukov MY, Park PJ (2008). Design and analysis of ChIP-seq experiments for DNA-binding proteins. Nat Biotechnol 26: 1351-1359.

Kilgore M, Miller CA, Fass DM, Hennig KM, Haggarty SJ, Sweatt JD et al (2010). Inhibitors of class 1 histone deacetylases reverse contextual memory deficits in a mouse model of Alzheimer's disease. Neuropsychopharmacology 35: 870-880.

Koch CM, Andrews RM, Flicek P, Dillon SC, Karaöz U, Clelland GK et al (2007). The landscape of histone modifications across $1 \%$ of the human genome in five human cell lines. Genome Res 17: 691-707.

Korzus E, Rosenfeld MG, Mayford M (2004). CBP histone acetyltransferase activity is a critical component of memory consolidation. Neuron 42: 961-972.

Koshibu K, Graff J, Beullens M, Heitz FD, Berchtold D, Russig H et al (2009). Protein phosphatase 1 regulates the histone code for long-term memory. J Neurosci 29 13079-13089.

Kouzarides T (2007). Chromatin modifications and their function. Cell 128: 693-705.

Kramer JM, Kochinke K, Oortveld MA, Marks H, Kramer D, de Jong EK et al (2011) Epigenetic regulation of learning and memory by Drosophila EHMT/G9a. PLoS Biol 9: e1000569.

Lacombe D, Patton MA, Elleau C, Battin J (1995). Floating-Harbor syndrome: description of a further patient, review of the literature, and suggestion of autosomal dominant inheritance. Eur J Pediatr 154: 658-661.

Landles C, Bates GP (2004). Huntingtin and the molecular pathogenesis of Huntington's disease. Fourth in molecular medicine review series. EMBO Rep 5 958-963.

Lee JS, Smith E, Shilatifard A (2010). The language of histone crosstalk. Cell 142 $682-685$

Levenson JM, O'Riordan KJ, Brown KD, Trinh MA, Molfese DL, Sweatt JD (2004). Regulation of histone acetylation during memory formation in the hippocampus. J Biol Chem 279: 40545-40559.

Liu R, Lei JX, Luo C, Lan X, Chi L, Deng P et al (2012). Increased EID1 nuclear translocation impairs synaptic plasticity and memory function associated with pathogenesis of Alzheimer's disease. Neurobiol Dis 45: 902-912.

Luger K, Mader AW, Richmond RK, Sargent DF, Richmond TJ (1997). Crystal structure of the nucleosome core particle at $2.8 \mathrm{~A}$ resolution. Nature 389: 251-260.

Mann RK, Grunstein M (1992). Histone H3 N-terminal mutations allow hyperactivation of the yeast GAL1 gene in vivo. EMBO J 11: 3297-3306.

Maurice T, Duclot F, Meunier J, Naert G, Givalois L, Meffre J et al (2008). Altered memory capacities and response to stress in p300/CBP-associated factor (PCAF) histone acetylase knockout mice. Neuropsychopharmacology 33: 1584-1602.

McQuown SC, Barrett RM, Matheos DP, Post RJ, Rogge GA, Alenghat T et al (2011). HDAC3 is a critical negative regulator of long-term memory formation. J Neurosci 31: 764-774.

McQuown SC, Wood MA (2011). HDAC3 and the molecular brake pad hypothesis. Neurobiol Learn Mem 96: 27-34. 
Mielcarek M, Benn CL, Franklin SA, Smith DL, Woodman B, Marks PA et al (2011). SAHA decreases HDAC 2 and 4 levels in vivo and improves molecular phenotypes in the R6/2 mouse model of Huntington's disease. PLoS One 6: e27746.

Minamiyama M, Katsuno M, Adachi H, Waza M, Sang C, Kobayashi Y et al (2004). Sodium butyrate ameliorates phenotypic expression in a transgenic mouse model of spinal and bulbar muscular atrophy. Hum Mol Genet 13: 1183-1192.

Monsey MS, Ota KT, Akingbade IF, Hong ES, Schafe GE (2011). Epigenetic alterations are critical for fear memory consolidation and synaptic plasticity in the lateral amygdala. PLoS One 6: e19958.

Morgado-Bernal I (2011). Learning and memory consolidation: linking molecular and behavioral data. Neuroscience 176: 12-19.

Mujtaba S, Zeng L, Zhou MM (2007). Structure and acetyl-lysine recognition of the bromodomain. Oncogene 26: 5521-5527.

Mutskov V, Gerber D, Angelov D, Ausio J, Workman J, Dimitrov S (1998). Persistent interactions of core histone tails with nucleosomal DNA following acetylation and transcription factor binding. Mol Cell Biol 18: 6293-6304

Myers FA, Chong W, Evans DR, Thorne AW, Crane-Robinson C (2003). Acetylation of histone $\mathrm{H} 2 \mathrm{~B}$ mirrors that of $\mathrm{H} 4$ and $\mathrm{H} 3$ at the chicken beta-globin locus but not at housekeeping genes. J Biol Chem 278: 36315-36322.

Nanney DL (1958). Epigenetic control systems. Proc Natl Acad Sci USA 44: $712-717$.

Nguyen PV, Abel T, Kandel ER (1994). Requirement of a critical period of transcription for induction of a late phase of LTP. Science 265: 1104-1107.

Oike Y, Hata A, Mamiya T, Kaname T, Noda Y, Suzuki M et al (1999). Truncated CBP protein leads to classical Rubinstein-Taybi syndrome phenotypes in mice: implications for a dominant-negative mechanism. Hum Mol Genet 8: 387-396.

Oliveira AM, Abel T, Brindle PK, Wood MA (2006). Differential role for CBP and p300 CREB-binding domain in motor skill learning. Behav Neurosci 120: 724-729.

Oliveira AM, Estevez MA, Hawk JD, Grimes S, Brindle PK, Abel T (2011). Subregion-specific p300 conditional knock-out mice exhibit long-term memory impairments. Learn Mem 18: 161-169.

Oliveira AM, Wood MA, McDonough CB, Abel T (2007). Transgenic mice expressing an inhibitory truncated form of p300 exhibit long-term memory deficits. Learn Mem 14: 564-572

Ordentlich P, Yan Y, Zhou S, Heyman RA (2003). Identification of the antineoplastic agent 6-mercaptopurine as an activator of the orphan nuclear hormone receptor Nurr1. J Biol Chem 278: 24791-24799.

Park PJ (2009). ChIP-seq: advantages and challenges of a maturing technology. Nat Rev Genet 10: 669-680.

Peart MJ, Smyth GK, van Laar RK, Bowtell DD, Richon VM, Marks PA et al (2005). Identification and functional significance of genes regulated by structurally different histone deacetylase inhibitors. Proc Natl Acad Sci USA 102: 3697-3702.

Peleg S, Sananbenesi F, Zovoilis A, Burkhardt S, Bahari-Javan S, Agis-Balboa RC et al (2010). Altered histone acetylation is associated with age-dependent memory impairment in mice. Science 328: 753-756.

Pepke S, Wold B, Mortazavi A (2009). Computation for ChIP-seq and RNA-seq studies. Nat Methods 6(11 Suppl): S22-S32.

Perez-Cadahia B, Drobic B, Davie JR (2011). Activation and function of immediateearly genes in the nervous system. Biochem Cell Biol 89: 61-73.

Pieretti M, Zhang FP, Fu YH, Warren ST, Oostra BA, Caskey CT et al (1991). Absence of expression of the FMR-1 gene in fragile $X$ syndrome. Cell 66: 817-822.

Pittenger C, Huang YY, Paletzki RF, Bourtchouladze R, Scanlin H, Vronskaya S et al (2002). Reversible inhibition of CREB/ATF transcription factors in region CA1 of the dorsal hippocampus disrupts hippocampus-dependent spatial memory. Neuron 34: 447-462.

Pokholok DK, Harbison CT, Levine S, Cole M, Hannett NM, Lee TI et al (2005). Genome-wide map of nucleosome acetylation and methylation in yeast. Cell 122: $517-527$.

Qi X, Hosoi T, Okuma Y, Kaneko M, Nomura Y (2004). Sodium 4-phenylbutyrate protects against cerebral ischemic injury. Mol Pharmacol 66: 899-908.

Rada-Iglesias A, Enroth S, Ameur A, Koch CM, Clelland GK, Respuela-Alonso P et al (2007). Butyrate mediates decrease of histone acetylation centered on transcription start sites and down-regulation of associated genes. Genome Res 17: 708-719.

Ricobaraza A, Cuadrado-Tejedor M, Perez-Mediavilla A, Frechilla D, Del Rio J, Garcia-Osta A (2009). Phenylbutyrate ameliorates cognitive deficit and reduces tau pathology in an Alzheimer's disease mouse model. Neuropsychopharmaco/ogy 34: 1721-1732.

Roth SY, Denu JM, Allis CD (2001). Histone acetyltransferases. Annu Rev Biochem 70: $81-120$

Rubinstein JH, Taybi H (1963). Broad thumbs and toes and facial abnormalities. A possible mental retardation syndrome. Am J Dis Child 105: 588-608.
Ryu H, Smith K, Camelo SI, Carreras I, Lee J, Iglesias AH et al (2005). Sodium phenylbutyrate prolongs survival and regulates expression of antiapoptotic genes in transgenic amyotrophic lateral sclerosis mice. J Neurochem 93: $1087-1098$.

Safe S, Kim K, Li X, Lee SO (2011). NR4A orphan receptors and cancer. Nuclear Receptor Signaling 9: e002.

Sakamoto K, Karelina K, Obrietan K (2011). CREB: a multifaceted regulator of neuronal plasticity and protection. J Neurochem 116: 1-9.

Sanchez R, Zhou MM (2009). The role of human bromodomains in chromatin biology and gene transcription. Curr Opin Drug Discov Devel 12: 659-665.

Schmitt M, Matthies H (1979). [Biochemical studies on histones of the central nervous system. III. Incorporation of [14C]-acetate into the histones of different rat brain regions during a learning experiment]. Acta Biol Med Ger 38: 683-689.

Schubeler D, MacAlpine DM, Scalzo D, Wirbelauer C, Kooperberg C, van Leeuwen $F$ et al (2004). The histone modification pattern of active genes revealed through genome-wide chromatin analysis of a higher eukaryote. Genes Dev 18: 1263-1271.

Sengupta N, Seto E (2004). Regulation of histone deacetylase activities. J Cell Biochem 93: 57-67.

Shahbazian MD, Grunstein M (2007). Functions of site-specific histone acetylation and deacetylation. Annu Rev Biochem 76: 75-100.

Shin JH, Li RW, Gao Y, Baldwin Rt, Li CJ (2012). Genome-wide ChIP-seq mapping and analysis reveal butyrate-induced acetylation of H3K9 and H3K27 correlated with transcription activity in bovine cells. Funct Integr Genomics 12: 119-130.

Stanton PK, Sarvey JM (1984). Blockade of long-term potentiation in rat hippocampal CA1 region by inhibitors of protein synthesis. J Neurosci 4 3080-3088.

Stefanko DP, Barrett RM, Ly AR, Reolon GK, Wood MA (2009). Modulation of longterm memory for object recognition via HDAC inhibition. Proc Natl Acad Sci USA 106: 9447-9452.

Steffan JS, Bodai L, Pallos J, Poelman M, McCampbell A, Apostol BL et al (2001). Histone deacetylase inhibitors arrest polyglutamine-dependent neurodegeneration in Drosophila. Nature 413: 739-743.

Suganuma T, Workman JL (2011). Signals and combinatorial functions of histone modifications. Annu Rev Biochem 80: 473-499.

Tabolacci E, De Pascalis I, Accadia M, Terracciano A, Moscato U, Chiurazzi P et al (2008). Modest reactivation of the mutant FMR1 gene by valproic acid is accompanied by histone modifications but not DNA demethylation. Pharmacogenet Genomics 18: 738-741.

Tanaka Y, Naruse I, Maekawa T, Masuya H, Shiroishi T, Ishii S (1997). Abnormal skeletal patterning in embryos lacking a single Cbp allele: a partial similarity with Rubinstein-Taybi syndrome. Proc Natl Acad Sci USA 94: 10215-10220.

Tang B, Di Lena P, Schaffer L, Head SR, Baldi P, Thomas EA (2011). Genome-wide identification of Bcl11b gene targets reveals role in brain-derived neurotrophic factor signaling. PLoS One 6: e23691.

Tian F, Marini AM, Lipsky RH (2010). Effects of histone deacetylase inhibitor Trichostatin A on epigenetic changes and transcriptional activation of Bdnf promoter 1 by rat hippocampal neurons. Ann NY Acad Sci 1199: 186-193.

Tsankova NM, Berton O, Renthal W, Kumar A, Neve RL, Nestler EJ (2006). Sustained hippocampal chromatin regulation in a mouse model of depression and antidepressant action. Nat Neurosci 9: 519-525.

Valor LM, Pulopulos MM, Jimenez-Minchan M, Olivares R, Lutz B, Barco A (2011). Ablation of $\mathrm{CBP}$ in forebrain principal neurons causes modest memory and transcriptional defects and a dramatic reduction of histone acetylation but does not affect cell viability. J Neurosci 31: 1652-1663.

van Belzen M, Bartsch O, Lacombe D, Peters DJ, Hennekam RC (2011). Rubinstein-Taybi syndrome (CREBBP, EP300). Eur J Hum Genet 19 preceeding 118-120.

Van Lint C, Emiliani S, Verdin E (1996). The expression of a small fraction of cellular genes is changed in response to histone hyperacetylation. Gene Expr 5: 245-253.

Vecsey CG, Hawk JD, Lattal KM, Stein JM, Fabian SA, Attner MA et al (2007). Histone deacetylase inhibitors enhance memory and synaptic plasticity via CREB:CBP-dependent transcriptional activation. J Neurosci 27: 6128-6140.

Vermeulen M, Carrozza MJ, Lasonder E, Workman JL, Logie C, Stunnenberg HG (2004). In vitro targeting reveals intrinsic histone tail specificity of the Sin3/histone deacetylase and N-CoR/SMRT corepressor complexes. Mol Cell Biol 24: 2364-2372.

Viosca J, Lopez-Atalaya JP, Olivares R, Eckner R, Barco A (2010). Syndromic features and mild cognitive impairment in mice with genetic reduction on p300 activity: differential contribution of p300 and CBP to Rubinstein-Taybi syndrome etiology. Neurobiol Dis 37: 186-194.

Volakakis N, Kadkhodaei B, Joodmardi E, Wallis K, Panman L, Silvaggi J et al (2010). NR4A orphan nuclear receptors as mediators of CREB-dependent neuroprotection. Proc Natl Acad Sci USA 107: 12317-12322. 
Waddington $\mathrm{CH}$ (1942). Canalization of development and the inheritance of acquired characters. Nature 150: 563-565.

Wang Z, Zang C, Cui K, Schones DE, Barski A, Peng W et al (2009). Genome-wide mapping of HATs and HDACs reveals distinct functions in active and inactive genes. Cell 138: 1019-1031.

Wansa KD, Harris JM, Yan G, Ordentlich P, Muscat GE (2003). The AF-1 domain of the orphan nuclear receptor NOR-1 mediates trans-activation, coactivator recruitment, and activation by the purine anti-metabolite 6-mercaptopurine. J Biol Chem 278: 24776-24790.

Waterborg JH (2002). Dynamics of histone acetylation in vivo. A function for acetylation turnover? Biochem Cell Biol 80: 363-378.

Wood MA, Attner MA, Oliveira AM, Brindle PK, Abel T (2006). A transcription factorbinding domain of the coactivator CBP is essential for long-term memory and the expression of specific target genes. Learn Mem 13: 609-617.

Wood MA, Kaplan MP, Park A, Blanchard EJ, Oliveira AM, Lombardi TL et al (2005). Transgenic mice expressing a truncated form of CREB-binding protein (CBP) exhibit deficits in hippocampal synaptic plasticity and memory storage. Learn Mem 12: 111-119.

Yeh SH, Lin CH, Gean PW (2004). Acetylation of nuclear factor-kappaB in rat amygdala improves long-term but not short-term retention of fear memory. $\mathrm{Mol}$ Pharmacol 65: 1286-1292.
Yoo YG, Na TY, Yang WK, Kim HJ, Lee IK, Kong G et al (2007). 6-Mercaptopurine an activator of Nur77, enhances transcriptional activity of HIF-1alpha resulting in new vessel formation. Oncogene 26: 3823-3834.

Youn HD, Liu JO (2000). Cabin1 represses MEF2-dependent Nur77 expression and Tcell apoptosis by controlling association of histone deacetylases and acetylases with MEF2. Immunity 13: 85-94.

Yun M, Wu J, Workman JL, Li B (2011). Readers of histone modifications. Cell Res 21: $564-578$.

Zeng L, Zhou MM (2002). Bromodomain: an acetyl-lysine binding domain. FEBS Lett 513: 124-128.

Zeng Y, Tan M, Kohyama J, Sneddon M, Watson JB, Sun YE et al (2011). Epigenetic enhancement of BDNF signaling rescues synaptic plasticity in aging. J Neurosci 31: 17800-17810.

Zhan Y, Du X, Chen H, Liu J, Zhao B, Huang D et al (2008). Cytosporone B is an agonist for nuclear orphan receptor Nur77. Nat Chem Biol 4: 548-556.

Zhou WW, Goren A, Bernstein BE (2011a). Charting histone modifications and the functional organization of mammalian genomes. Nat Rev Genet 12: 7-18.

Zhou Z, Yuan Q, Mash DC, Goldman D (2011b). Substance-specific and shared transcription and epigenetic changes in the human hippocampus chronically exposed to cocaine and alcohol. Proc Natl Acad Sci USA 108: 6626-6631. 